Chapter 10

\title{
Early Stages of Industrial Design Careers
}

\author{
Inalda A. L. L. M. Rodrigues and Denis A. Coelho \\ Additional information is available at the end of the chapter \\ http://dx.doi.org/10.5772/52857
}

\section{Introduction}

This chapter seeks to contribute to the elucidation of, not only, industrial designers, but also of educational institutions, both domestic and international, about how important it is to follow the development of markets and technology, in order to incorporate this in the curricula of future designers, with a view to further aid their transition to the labour market.The methodology set for the completion of the work was divided into two stages. Initially, literature review was used to underpin research and then empirical work was carried out in the search for new information and clarifications from the world of praxis.

The primary data collection was carried out using data collection instruments, which consisted of two questionnaires, applied to two distinct groups of respondents, namely, industrial designers and employers. The application of a survey instrument was chosen because of its ability to enable distance of the researchers to the respondenys and more autonomy than, for example, interviews (Almeida and Pinto, 1995). Questionnaires free the researcher from presence at the time of the response by the respondent, enabling an indirect interaction (Carmo and Ferreira, 1998). The dissemination of questionnaires to industrial designers was performed with the support of the Portuguese Design Centre, which contributed to the high number of respondents achieved (141).

\subsection{Scope of the research}

As this chapter reports on a study on the prospects for job market integration of industrial designers, it was necessary to point the investigation in a first phase to the jobs that are available in countries like Portugal, Germany, France, Italy, UK, Canada, Spain, United States of America, Macau, Brazil, East Timor, Guinea Bissau, São Tomé and Principe, Mozambique, Angola and Cape Verde, in order to unveil the true extent of demand for the profession of industrial designer in the Lusophone (Portuguese Speaking) Space, and Western Europe and 
the United States and Canada. The authors deliberately chose to focus this study on entrepreneurship and its importance for the industrial designer, as well as on the contents of training that are more valued by employers of these professionals. The authors chose to present the results of the survey of businesses employing industrial designers and of industrial designers in the final parts of the chapter. The focus of the chapter lies also to a greater extent on the first phase of the career of industrial designers, rather than on later stages, where the range of career paths is more diversified and more difficult to cover in a work of this nature. It is also believed that the initial phase of the designer's career is a critical stage for the affirmation of the individual professional and therefore it arouses a very high level of interest as an object of research.

\section{Opportunities for integration of industrial designers in working life}

In pursuing the proposed aims, it was necessary to define criteria for the selection of job advertisements that would be examined. Given the impossibility of collecting all the available advertisements, during the time in which the study took place, because of insufficient resources, information was collected only in the form of sampling. Advertisements were retrieved by searching the Internet, specifically those clearly aimed at industrial, product, or equipment designers and that provided some information on sector of work, on the required qualifications, and on the skills and software knowledge preferred. In addition, the collection was limited to twenty offers for Portugal, and about a third of this amount to offers from each one of the other countries covered in the research that was done.

\subsection{National context (Portugal)}

The analysis in this section addresses the opportunities for integration into working life of industrial designers through an Internet search of job offers during the extended time period from October 2010 to February 2011, in Portugal. Job offers for positions in the field of industrial, product and equipment design were sought and identified. In Portugal, the regions that have a higher rate of development in relation to industrialization, are those where there is a greater number of job offers for industrial designers to be found, in particular, the central region (in and around the cities of Lisbon and Leiria) and the Northern region (in and around the cities of Porto and Braga). Among the most requested features in the offers were product designers with emphasis on the development of innovative products that would make a difference by strengthening the capacity of differentiation in highly competitive environments.

The characteristics and skills most valued are holding at least a degree in design (bachelors and masters are also required in some cases) and having experience in mastering the instrumental and technical means necessary for the conceptual development of new products. Designers must especially master the use of software such as Illustrator, Photoshop ${ }^{\mathrm{TM}}$ and 3D tools (Solidworks ${ }^{\mathrm{TM}}$, Rhino ${ }^{\mathrm{TM}}$, ProE ${ }^{\mathrm{TM}}$ ). Most advertisements aim at designers who have the 
ability to speak multiple languages, mainly English but also French, German and Spanish, besides their native language.

Regarding interpersonal and relational skills, applicants must show that they are dynamic, balanced, revealing a character that is suitable to work as a team member and having an entrepreneurial, creative and innovative attitude is especially valued. Almost every offer seeks experienced professionals with at least 2 years of experience, to serve in the furniture and electronics industries, among others. The search for trainees (without experience) was not found to be very expressive.

In many job offers, the prospective employer was not specified, and with regard to the benefits (wages) in return for the services to be rendered, it is noted that only a few of the job offers surveyed did declare wage values.

\subsection{International context}

The analysis carried out in this section discusses the opportunities for integration into working life of industrial designers which were unveiled through a survey of international job offers available on the Internet, in the period from October 2010 to February 2011. The survey focused on job offers in the area of industrial, product and equipment design, identifying the positions advertised, the prerequisites for filling each vacancy and the benefits offered. United States, Australia, Germany, France, Italy, UK, Canada, Spain and Brazil were the countries included, given the perception of the authors that in these countries there are many companies looking for professionals in the field of industrial design. Regarding Portuguese speaking countries and territories, other than Angola, Brazil and Portugal, including Cape Verde, Mozambique, Macau, East Timor, Guinea-Bissau and São Tomé and Príncipe, the demand for industrial designers does not seem to have much expression, judging from the period when job offers placed on the Internet were surveyed.

Among the most requested skills for the industrial designer, emphasis appears in many cases on packaging design and development of innovative products. The most valued qualifications concern holding at least a Bachelor degree in a design specialization. Besides up-to-date skills in 3D solid modelling, some companies place a premium on knowledge of CATIA software and having good overall designer computer skills, including experience with webpage design. Almost every offer surveyed sought experienced professionals with at least 3 years of experience.

\subsection{Discussion on opportunities for integration in active life}

The survey carried out at national level about opportunities for integration in working life for industrial designers showed that, with regard to experience, companies often want designers with some experience and rarely ask for those looking for their first job. In relation to compensation, very few companies disclosed earning ranges in their offers.

International demand for industrial designers is significant, both in European countries and globally. In what concerns Portuguese-speaking countries, with the exception of Brazil and 
Portugal, the demand does not seem to be expressive. Regarding remuneration, almost all companies disclosed the salary offered, with the monthly value changing from country to country and mostly between 1000 and 3000 USD. The most common areas of action ranged from electronics to footwear, including household appliances, among others. In terms of experience, companies often seek designers with some experience and rarely ask for those seeking their first job.

\section{Importance of entrepreneurship for the success of the industrial designer}

The development of innovative products and improving existing products is a complex business effort, involving the integration of various skills, from design to manufacture through design and marketing. The practice of entrepreneurship appears to be increasing worldwide as a career option, against the backdrop of socio-economic difficulties undermining many economies and countries and reducing opportunities for those wishing to enter the labour market. However, the practice of entrepreneurship coexists with the failure of many organizations, due to the low levels of education of entrepreneurs and heir reduced motivation to use management tools that would enable them to upgrade their activities.

Design has proved an important tool in creating value through innovation. The growing appreciation of the profession in the world has highlighted the urgent need of education in design to be targeted to deal with the globalized and extremely competitive economy and job market. In this sense, design education must be addressed as to support and nurture young designers, facilitating their entry in the job market, along with the dynamism and expansion of design as a factor in creating value for companies and nations.

As an example of the pathways of professional affirmation of designers, entrepreneurship, at various stages of the careers of designers, can be studied from both a theoretical standpoint, and considering a national reality. In this context, and by way of example, this section of the paper presents a technological project for sustainable design and outlines the contours of a proposal for social entrepreneurship based on that project, aiming to contribute to community development.

\subsection{Sustainable design project with a view to entrepreneurship in collabouration with the local community (Niassa - Mozambique) to contribute to local development}

This section presents a design project with a view to sustainable entrepreneurship, entitled "Development of sustainable integrated solutions for the northern provinces of Mozambique - Ecotourism." The project consisted of the development (analysis and design) of a hot air balloon and an infra- structure for the production of biogas with concerns for environmental sustainability, to support ecotourism in a group of communities. For this project, several objectives were thus outlined, with key points that should be achieved, such as the use of ecological materials, achieving an aesthetically acceptable, innovative, affordable, competitive and uniform design. 
Ecotourism is a segment of tourism that explores the environmental, natural and cultural heritage, encourages conservation and seeks the formation of environmental awareness through the interpretation of the environment and promoting the welfare of populations. In this project, it was chosen to develop a hot air balloon. The idea was to create the balloon to support human recreational activity, through geographical exploration from an aerial perspective in a non-polluting way, and thus contribute to rural poverty alleviation and sustainable development in rural communities of the northern provinces of Mozambique, and Niassa in particular. The aim was to create a sightseeing tour promoting touristic housing where Eco tourists would be able to stay with the native population, and partake in the activities of these traditional communities. Through this practice, the income would go directly to families and community funded projects in health, education, road construction, among other domains.

Mozambique is a country in the east coast of southern Africa, bordered to the north by Zambia, Malawi and Tanzania, to the east by the Mozambique Channel and the Indian Ocean, and to the south and to the southwest by South Africa and to the west by Swaziland and Zimbabwe. The province of Niassa was selected for the realization of the ecotourism route conceived (approximately $120 \mathrm{~km}$ ) - Niassa - Lichinga - Dias - Maniamba - Metangula.

The chosen route begins in Lichinga, the capital of Niassa. The first stop would be Dias, about $46 \mathrm{~km}$ away. The next stop would be Maniamba, about $43 \mathrm{~km}$ from Dias. Departing from Maniamba, the next destination would be Metangula, about $30 \mathrm{~km}$ away. Given that the maximum speed for safe travel by balloon is up to $20 \mathrm{~km} / \mathrm{h}$ (always depending on the weather and wind) and that the autonomy of the balloon is usually 3 hours of flight, it is expected that the route chosen would enable a comfortable and safe journey through the air.

As an air vessel without mechanical handling and dependent on wind currents, weather monitoring becomes essential for the safe displacement of the hot air balloon. The ideal conditions for balloon flights are early in the day, with great visibility and light winds, with speeds up to 10 knots $(18.5 \mathrm{~km} / \mathrm{h}$ or $5.2 \mathrm{~m} / \mathrm{s})$. The wind regime in Mozambique is essentially influenced by the circulation of the atmosphere in southern Africa and the main currents blow from southeast. Mean annual temperatures vary between $23^{\circ} \mathrm{C}$ and $26^{\circ} \mathrm{C}$. In areas of high altitude, these are less than $23^{\circ} \mathrm{C}$. The warmest and most moist months are October to February.

An anaerobic digester is a device used to produce biogas, a mixture of gases, mainly methane, produced by bacteria that digest organic matter under anaerobic conditions (in the absence of oxygen). A bio-digester is a chemical reactor in which chemical reactions of biological origin take place. The biogas can be used as fuel for the hot air balloon instead of natural gas or gas obtained from oil, both extracted from mineral reserves.

This project was presented on July $8^{\text {th }}, 2010$ in Maputo, Mozambique, at the international symposium "Towards a research agenda for development ergonomics in Mozambique". Other projects were developed onwards as a consequence of the afore-mentioned symposium and were reported by Couvinhas et al. (2012) and by Coelho et al. (2012).

The results to be achieved with this Ecotourism project based on a hot air balloon that runs on biogas created from bio-digesters placed locally (fueled by organic waste from livestock) 
include enabling a scientific, historical and cultural basis for the stay of tourists in rural communities, while practicing a kind of eco-tourism, but one that is also exciting and adventurous. Bio-digesters and tourist facilities are to be placed on ground stations, from village to village, to foster increased income for communities and hence an economic boost. Image renders of the project developed are shown in Figures 1 to 3.

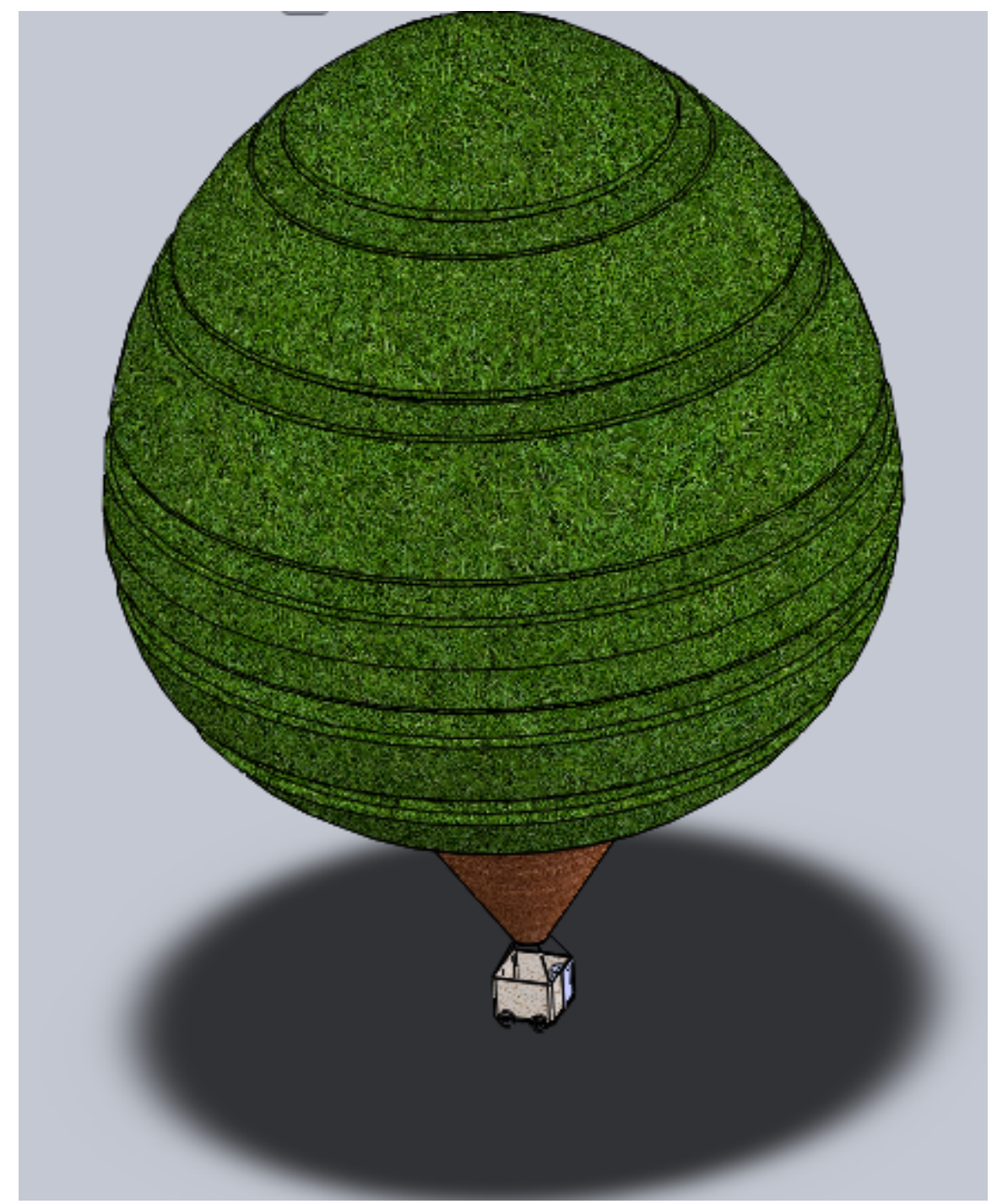

Figure 1. Render of Hot Air Balloon Design 


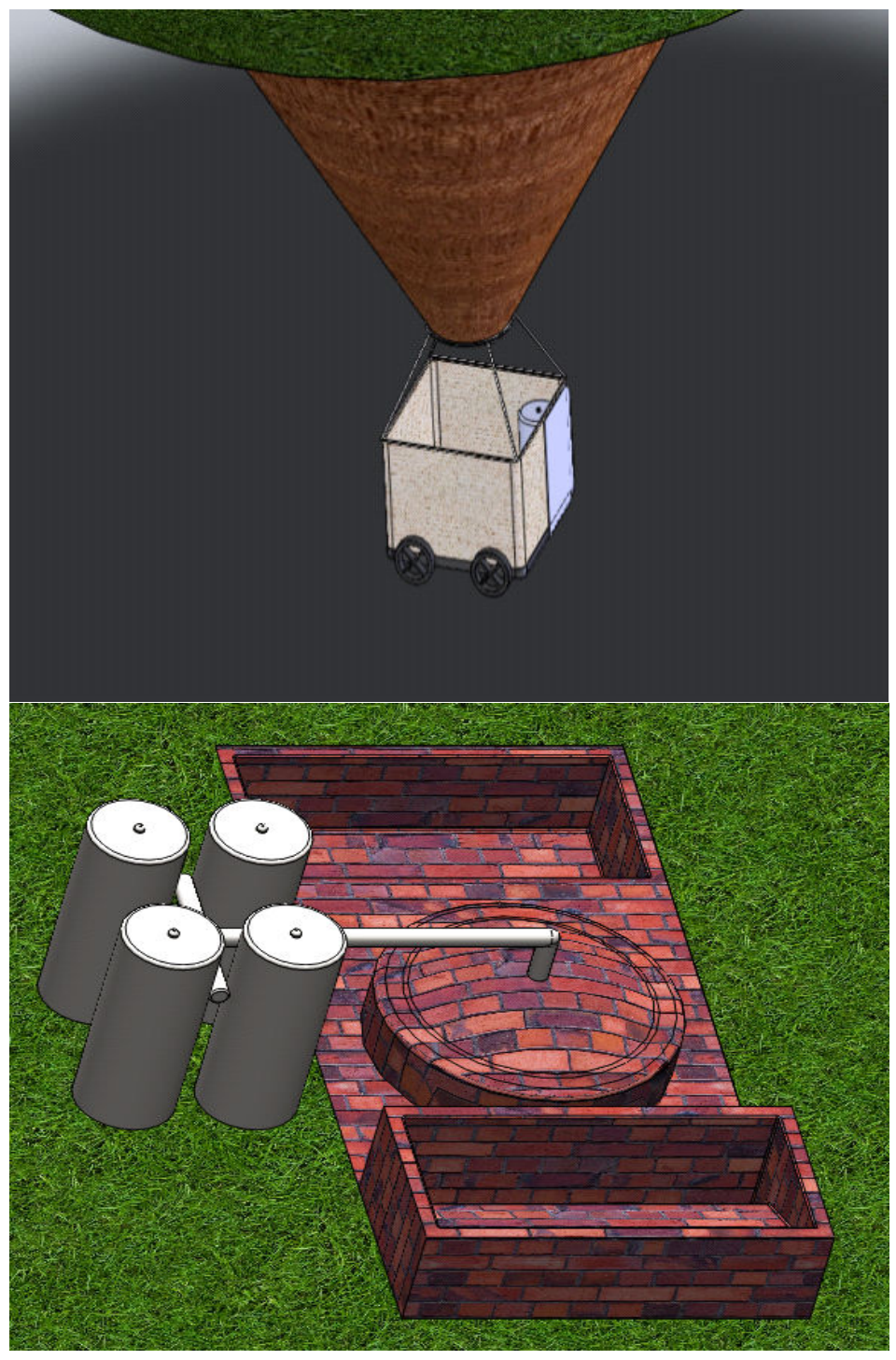

Figure 2. Renders - Basket and Bio-digester 


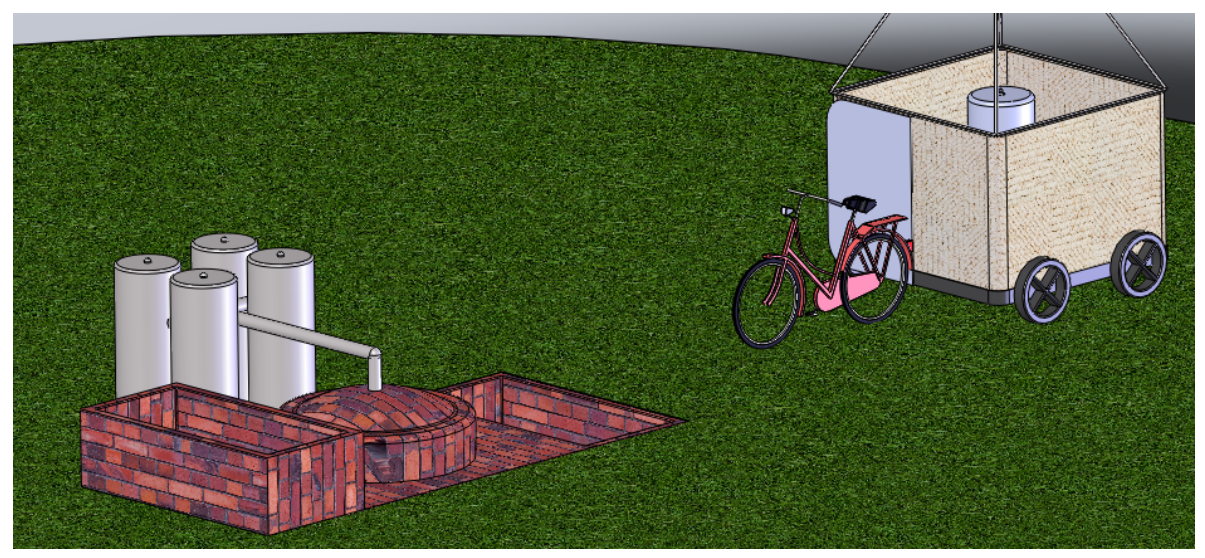

Figure 3. Image Renders of Bio-digester, Bicycle and Basket

\subsection{Discussion on design and entrepreneurship}

The elements gathered and discussed enable considering that in the current context, and the geographic scope considered, entrepreneurship is important for the affirmation of the industrial designer, since it is a way of setting up business structures, albeit small or very small, which allows the development of a corporate culture aligned with the activity of industrial designers. The development of this culture itself can sometimes be difficult in larger and established corporate structures, with other cultures prevailing in these cases (e.g., management, economics, and engineering). This clash of mentalities and forms of action among professionals may in some cases jeopardize productivity and personal fulfillment of industrial designers in the aspects that are paradoxically more valued (creativity and innovation). Thus, entrepreneurship in industrial design can be seen as a way to foster a culture of innovation and creativity, benefiting all stakeholders in the socio-economic fabric, as in many cases these micro and small businesses created by designers serve large companies, while maintaining their independence, or even have the ability to directly generate other profitable businesses based on their innovative projects. This section has presented a project by the first author, a venture into entrepreneurship based on a comprehensive concept for ecotourism and community development.

\section{Information collected from surveys}

This section presents the condensed results of two surveys conducted. Complete results can be found in Rodrigues (2011). Entry into the labour market occurs relatively early, as most designers surveyed did not wait more than two years to have their first professional experience, which usually occurred in small companies. One of the main difficulties faced by these professionals was working with software that was not known to them. This factor is also 
considered by employers as one of the biggest problems that designers face when they seek to succeed in the labour market.

In relation to the entrepreneurial spirit of the surveyed designers, the study demonstrated that most of the designers who had had an innovative idea or business during academic training, and when trying to realize this idea had been unable to get financial support for their development, at present, these professionals, come to think about having their own business and thus creating their own jobs. On the analysis of employment held, designer respondents hold a positive spirit, since the majority considered that they had stable employment prospects. As for their salary, most designers think that the salary they receive is not appropriate to the functions they perform.

In terms of the assessment of training for designers, employers positively assess, in general, the training in relation to software taught, though most of them think that more recent software should also be included. Regarding the development of entrepreneurial skills and knowledge of current and emerging technologies, these are aspects that employers consider that need to be reinforced in the training of these professionals.

Considering the answers given by the designers, these suggest that they acknowledge the lack of close contact with business reality during their higher education. The reason for this lack of contact is related to teaching that focuses on many cases in a set of theoretical knowledge that often are not demonstrated or tested by future designers and does not focus enough on practice in the field.

In terms of skills needed to succeed in today's job market and what can be expected for the near future, it is important to highlight some skills related to team performance, namely, the ability to work as a team. Interestingly, throughout the duration of academic training, the ability to work in a team is valued more by teachers than by student-designers, but this capability becomes more valued by designers when they enter working life.

Currently, what is sought in the performance of designers is the mastery of technical skills combined with knowledge about new technologies, but also a focus on creativity and innovation capacity paired with mastery of a wide range of interpersonal skills to enabling adaptation to the evolving context of professional duties.

\subsection{Skills most valued per industrial design specialty}

For each type of trajectory in industrial design, there exists one or more important and beneficial skill and competency for every type of career path. There are several types of paths, activities or areas of expertise where industrial designers specialize in, such as furniture, footwear, electronics, appliances, toys, jewellery, packaging, automotive, among others.

For the design of furniture, for example, according to data collected in the questionnaire to employers, the skills most valued were knowledge of materials, creativity and CAD, while the audiovisual editing or video editing skills were not very much valued. For the design of footwear, the skills most valued are CAD, while the skills of image editing and art were not highly valued. For the design of electronic equipment, mastery of the area of materials, CAD 
and prototyping were the skills most valued, while the art and video editing skills were not valued. For the design of appliances, skills most valued are mastery of CAD, materials, prototyping and design methodologies. For jewelry design, skills most valued are talent and creativity. For the design of toys, the skills that are most valued concern the area of materials and creativity. Expertise in packaging design, should be grounded on knowledge of types of materials, on CAD mastery and on creativity.

\subsection{Discussion on training and skills top ranked for each type of specialization}

Designers and their employers value a variety of factors and skills, with emphasis on creativity and the ability to bring innovation directed to increased market penetration and shares. Designers value the skills that will help them stand out and gain prestige and professional recognition. Designers are required to possess not only technical skills, but also mastery of methodologies for the execution and implementation of design projects and knowledge of the manufacturing methods.

\section{Conclusion}

The work reported in this chapter shed light on the content of job offers in the area of industrial design, analyzed in relation to skills, qualifications and experience required. Through the surveys conducted, empirical data was gathered that supplemented literature review of studies to enhance the attainment of the objectives proposed for the study. Most designer respondents aspire to become professionally independent of their employer, and to create their own business.

This chapter aimed to analyze and understand the employment opportunities for the profession of industrial designer and their qualifications that are most conducive to recruitment, adopting a national perspective and an international perspective. To achieve this, a twopronged approach was developed aimed, firstly, to identify pathways to integration in the labour market by industrial designers at the national level, within the Portuguese language space and at the international level, in order to understand the importance of training and other conditioning factors for these paths. On the other hand, work proceeded through surveys to enable the unveiling of the training components seen as critical to employers, and at the same time, this was done to try to envision their future needs in order to provide feedback to the training institutions and enhance effective training and consequently employability. As an example of the pathways of professional affirmation of designers, entrepreneurship, at various stages of the careers of designers, has been studied both from a theoretical standpoint, and considering the socio-economic reality. In this context, and by way of example, the chapter presented a technological project for sustainable design and outlined the contours of a proposal for social entrepreneurship based on that project, aiming to contribute to community development. The work developed and reported in this chapter shed light on a perspective of current job offers in this area, analyzed in relation to the skills, qualifications and experience required. Based on two questionnaire studies made (one questionnaire was addressed to designers 
active in the Portuguese language space, with 141 respondents, and the other was addressed to heads of enterprises within the Portuguese language space (responses were only collected in Portugal) employing designers, with 19 responses collected), empirical contributions were collected to complement the literature review studies conducted to enhance the attainment of the objectives proposed for the study.

With this work, it was possible to develop an empirical perspective of the challenges facing industrial designers' early career, focusing in particular on designers trained in Portugal. Moreover, the study presents contributions for designers, entrepreneurs, companies and schools that provide training in this area, which may help these groups with tangled interests to pursue their goals more effectively. As civilization makes the transition from the industrial era to one of sustainability, educational leaders around the globe ought to implement a learning system that prepares its young people for life in a unified society. Zinser (2012) provides a starting point to explore what skills and concepts students should be studying to lead the future.

\section{Future work}

After the presentation of the findings it is important to highlight some issues that provide some recommendations for future research. Based on the results that were achieved, there are clues about what to explore in future research.

As proposals for future work, springing from the results of the present work, one may consider:

- Development of empirical reality-based assessment of the design methodologies used by the designers and companies that employ them.

- Exploration of any differences controlled for gender between objectives and practices found in businesses and especially in companies run by designers.

Moreover, some suggestions for implementation by institutions to improve and adapt to meet the challenges encountered in academic education of industrial designers may be outlined:

- Universities / schools should seek to monitor the changes taking place in the employment marketplace, checking and continuously adjusting their programmes in industrial design to the market, in continuity and in anticipation, in order to respond more effectively to the level of training of designers demanded by employers.

- Training of designers should no longer be exclusively focused on the mastery of techniques, technologies and methodologies, which in itself is no longer enough, to become much more focused on knowledge of how to carry out interactions, e.g. learning to communicate, learning how to lead, learning and practicing teamwork, as well as enhancing innovation and creativity skills.

- Institutions should also focus increasingly on acquisition and mastery of technical skills, maintaining and even increasing incidence on personalized design skills. 
- Providing students with intensified and perseverant contacts and experiences with the reality of companies, either through internships or by carrying out real projects that are developed in partnership with businesses, although of an intrinsic curricular nature.

\section{Acknowledgement}

The work reported in this chapter was part of the Master of Science Thesis of the first author, supervised by the second author.

\section{Author details}

Inalda A. L. L. M. Rodrigues and Denis A. Coelho

Universidade da Beira Interior, Portugal

\section{References}

[1] Almeida, João Ferreira de Pinto and José Madureira (1995), Investigação nas Ciências Sociais (Research in the Social Sciences), Editorial Presença, Lisbon.

[2] Carmo, Hermano and Manuela Malheiro Ferreira (1998). Research Methodology: a guide for self-learning, Open University, Lisbon.

[3] Coelho, Denis. A., Patricia, R., Ferrara, Ana. F., \& Couvinhas, Tânia. M. Lima and Jake K. Walter (2012). Macroergonomic aspects in the design of development programs in IDCs. WorkA Journal of Prevention, Assessment and Rehabilitation, 41, 2651-2655.

[4] Couvinhas, Ana. F., Patricia, R., Ferrara, Denis. A., Coelho, Sinezia., Jorge, \& Jake, K. Walter (2012). Ergonomic considerations for a systemic approach: the millennium maize mills project in northern Mozambique. WorkA Journal of Prevention, Assessment and Rehabilitation, , 41, 568-575.

[5] Rodrigues, Inalda Araci do Livramento Lopes Mota (2011). Prospects for integration into the labour market of Industrial Designers. Dissertation for the Degree of Master in Industrial Design Engineering, Department of Electromechanical Engineering, Faculty of Engineering, University of Beira Interior, Covilhã, Portugal, 128pp.

[6] Zinser, Richard (2012). A curriculum model of a foundation for educating the global citizens of the future. On the Horizon, Iss.: 1, 20, 64-73. 